\title{
REFUGEE DETENTION CENTRE: HUMANITY VS NATIONAL SECURITY
}

\author{
Ninon Melatyugra \\ Alumni Fakultas Hukum UKSW angkatan 2008 dan Pemerhati HAM \\ Korespondensi: ninon.melatyugra@gmail.com
}

\begin{abstract}
Abstrak
Hukum internasional mengakui refugee sebagai suatu entitas yang memiliki kepentingan kemanusiaan selama mencari perlindungan di luar negaranya dari penyiksaan yang terjadi di negaranya. Sebagai konsekwensi, setiap negara mempunyai kewajiban erga omnes untuk memberi perlindungan terhadap para refugee di negara tersebut. Sayangnya dalam praktik, terdapat ketidakseimbangan antara kepentingan manusiawi dan kepentingan keamanan nasional. Artikel ini menunjukkan ketidakseimbangan kedua posisi dengan mengambil fokus pada Detention Centre di Australia, sebuah negara yang telah meratifikasi the 1951 Convention relating to the Status of Refugees. Penahanan administrasi dan ketidaktransparanan penilaian keamanan yang dilakukan oleh ASIO merupakan dua faktor utama berlatarbelakang keamanan nasional yang telah melemahkan posisi kepentingan kemanusiaan. Artikel ini juga menawarkan dua solusi untuk mengatasi masalah; pertama, batasan penahanan administratif harus dilakukan untuk menjamin hak hukum para refugee selama proses pengajuan visa; kedua, transparansi penilaian keamanan untuk menciptakan check-and-balance antara pemerintah Australia dan refugee dalam menentukan status visa para refugee.
\end{abstract}

Kata-kata Kunci: Refugee; Penahanan; Kemanusiaan; Keamanan, ASIO.

\begin{abstract}
International law recognizes refugee as an entity who possesses humanity interest while seeking for asylum outside his/her country from persecution in his/her country. As a consequence, each state has an erga omnes obligation to give asylum to refugees in its country. Unfortunately in practice, there is a lack of balance between humanity interest and national security interest. This article shows the imbalance of both position by taking focus on Detention Centre in Australia, a country that has ratified the 1951 Convention relating to the Status of Refugees. Administrative detention and intransparency of security assessment exercised by ASIO are two main factors with the national security background that have weakened the position of humanity interest. This article also proposes two solutions to tackle the problems; first, limitation of administrative detention must be undertaken to guarantee refugee's legal right during the visa application process; second, transparency of security assessment in order to create check-and-balance position between Australian Government and refugee in determining refugee's visa status.
\end{abstract}

Key Words: Refugee; Detention; Humanity; Security; ASIO. 


\section{PENDAHULUAN}

Pada tanggal 26 Agustus 2001, sebuah kapal Norwegia bernama MV Tampa tanpa ijin memasuki wilayah perairan Australia dengan jarak 75 mil dari Christmas Island. ${ }^{1}$ Kapal yang sebelumnya berlabuh dari Indonesia tersebut membawa sekitar 450 penumpang yang dominan berasal dari Afghanistan yang sedang berusaha mencari perlindungan di negara lain dari situasi perang di negaranya. Empat mil sebelum mencapai Christmas Island, otoritas maritim Australia memberi perintah kepada kapten kapal, Arne Rinnan, untuk menghentikan kapalnya dan kembali ke perairan internasional. Pada akhirnya kapal yang berisi refugee tersebut diperintahkan oleh otoritas maritime Australia menuju Detention Centre.

Peristiwa MV Tampa ini menjadi salah satu kasus internasional yang menunjukkan adanya benturan kepentingan antara kepentingan humanity yang dibawa refugee dengan kepentingan national security suatu negara. Di satu sisi, terdapat suatu kepentingan humanity yang dimiliki oleh penumpang MV Tampa sebagai refugee, atau biasa juga disebut asylum seeker. ${ }^{2}$ Namun di sisi lain, negara memiliki kedaulatan untuk menjaga wilayahnya dari illegal immigrant. Tulisan ini akan mengulas bagaimana posisi refugee dalam kepentingan humanity dan national security berdasarkan hukum internasional dan hukum nasional Australia.

\section{PEMBAHASAN}

\section{Refugee: Imigrasi Legal Berlatarbelakang Kepentingan Humanitarian}

Munculnya kepentingan refugee berawal dari Perang Dunia Kedua (19391945) yang mengakibatkan jutaan penduduk keluar dari negaranya untuk menghindari perang dan mencari perlindungan di Eropa (dominan di negara Jerman, Austria, dan Italia). ${ }^{3}$ Refugee adalah target tindakan kekerasan dan intimidasi karena dipandang sebagai komunitas yang berbeda dengan komunitas lokal di sekitarnya sehingga mendapat tekanan untuk meninggalkan wilayah tempat tinggalnya dan mencari perlindungan di wilayah lain. ${ }^{4}$ Pergerakan refugee tersebut kemudian menjadi kasus berskala internasional yang memberi konsekwensi pada negara "first country of asylum”, negara pemberi perlindungan kepada refuge $e^{5}$, untuk

John Ewing, 'Case 30: Universal Human Rights? The Case of MV Tampa' <http:// www.oup.com.au/_data/assets/pdf_file/0020/125615/Case_30.pdf > diakses 18 Maret 2014.

2 Perbedaan istilah refugee dan asylum seeker terletak pada proses aplikasi visa. Asylum seeker merupakan istilah untuk pengungsi yang didefinisikan pada The 1951 Convention relating to the Status of Refugees namun belum mendapatkan visa sebagai seorang refugee.

3 David Kennedy, 'International Refugee Protection' (1986) 8 Human Rights Quarterly 1, 3.

$4 \quad$ Kate Jastram dan Marilyn Achiron, 'Refugee Protection: A Guide to International Refugee Law' 6 <http://www.refworld.org/pdfid/3cd6a8444.pdf> diakses 18 Maret 2014.

5 Stephen H. Legomsky, 'Secondary Refugee Movements and the Return of Asylum Seekers to Third Countries: The Meaning of Effective Protection' (2003) 15 International Journal of Refugee Law 567, 571. 
melindungi hak dan kepentingan sah dari refugee dalam lingkup repatriation atau resettlement-and-reestablishment. ${ }^{6}$

Legitimasi hak seorang refugee dicakup dalam Artikel 14(1) the Universal Declaration of Human Rights (1948) yang menyatakan: "Everyone has the right to seek and to enjoy in other countries asylum from persecution" yang kemudian diatur lebih spesifik dalam Convention relating to the Status of Refugees (1951) (Konvensi Refugee) sebagai lex specialist. Konvensi Refugee mendefinisikan refugee sebagai: “ $A$ person who is outside his/her country of nationality or habitual residence; has a well-founded fear of persecution because of his/her race, religion, nationality, membership in a particular social group or political opinion; and is unable or unwilling to avail himself/herself of the protection of that country, or to return there, for fear of persecution." Berdasarkan definisi tersebut maka seseorang dapat dianggap sebagai refugee apabila: (a) berada di luar negaranya saat konflik terjadi; (b) mengalami penyiksaan karena ras, agama, kebangsaan, keanggotaan dalam kelompok sosial atau politik; (c) tidak mendapat perlindungan dari negaranya atas penyiksaan yang telah disebutkan di poin $b$.

Latar belakang refugee mencari perlindungan umumnya karena faktor: a. Escape Persecution (perlakuan tidak adil) karena agama, ras, keanggotaan dalam kelompok sosial.

b. Perang, seperti pada tahun 1979 saat USSR menginvasi Afghanistan sehingga menyebabkan 6 jutaan penduduk Afghanistan melarikan diri ke negara tetangga seperti Iran dan Pakistan.

c. Persecution seperti etnik minoritas the Roma yang hidup di negaranegara bagian Eropa timur yang menderita kekerasan rasis, kondisi kehidupan miskin, dan bentuk kekerasan lainnya.

d. Melawan pemerintahan seperti pada tahun 2002 saat banyak anggota dari the Movement for Democratic Change ditahan dan menghadap kasus kekerasan karena melawan pemerintahan Zimbabwe. ${ }^{7}$

Pada tahun 2012, Amerika Serikat telah menerima 58.179 refugee dari berbagai negara. ${ }^{8}$ Tiga negara asal refugee terbesar dalam statistik refugee tersebut adalah Bhutan, Burma, Irak. Di tahun yang sama, Australia memberi Protection Visa pada refugee yang dominan berasal dari Afghanistan, Iran dan Irak. ${ }^{9}$ Peran Amerika Serikat, Australia dan negara-negara lain penerima refugee menunjukkan bahwa memberikan perlindungan terhadap

\footnotetext{
Preambule 1946 Constitution of the International Refugee Organization.

Cath Senker, Migration and Refugees (Evan Brothers Limited 2008) 12-18.

Daniel C. Martin dan James E. Yankay, 'Annual Flow Report: Refugees and Asylees: 2012' 1 <http://www.dhs.gov/sites/default/files/publications/ois_rfa_fr_2012.pdf> diakses 18 Maret 2014.

9 Department of Immigration and Citizenship, 'Asylum Statistic - Australia: Quarterly Tables March Quarter 2013' 2 <http://www.immi.gov.au/media/publications/statistics/asylum/_files/ asylum-stats-march-quarter-2013.pdf> diakses 20 Maret 2014.
} 
refugee merupakan tanggung jawab masyarakat internasional.

Perlindungan diplomatik dalam litigasi internasional adalah tanggung jawab setiap negara penerima refugee. ${ }^{11}$ Tanggung jawab ini kemudian melahirkan kewajiban erga omnes bagi setiap negara di taraf internasional untuk memberikan perlindungan terhadap refugee berdasarkan latar belakang humanity sebagai bagian dari pemenuhan hak asasi setiap orang. ${ }^{12}$ Setiap negara berkewajiban untuk menerima refugee meski dalam kondisi illegal entry/stay, suatu diskresi terhadap peraturan imigrasi setiap negara. ${ }^{12}$

Hukum migrasi Australia mendefinisikan "Lawful non-citizen" sebagai "A non-citizen in the migration zone who holds a visa that is in effect is a lawful non-citizen." ${ }^{13}$ Maka secara a contrario, seseorang yang memasuki wilayah Australia tanpa visa/izin akan dianggap sebagai imigran yang tidak sah/illegal dan pemerintah Australia berhak melakukan penahanan terhadapnya. Secara garis besar, kategori unlawful non-citizen meliputi: a. Setiap orang yang berusaha memasuki wilayah negara tanpa visa, seperti kapal tanpa ijin;

b. Setiap orang yang telah memasuki wilayah negara dengan visa, namun tetap berada di Australia saat masa visa berakhir (overstayers);

c. Setiap orang yang melanggar ketentuan kondisi visa, seperti ketentuan bekerja yang ada dalam aturan jenis visa. ${ }^{14}$

Pada tahun 2012-2013, sebanyak 18.119 refugee mendarat di Australia sebagai Illegal Maritime Arrivals (IMA). ${ }^{15}$ Refugee yang datang menggunakan kapal tanpa visa tersebut biasa dikenal dengan istilah 'boat people' atau 'the queue jumpers' ${ }^{16}$ Berdasarkan hukum migrasi Australia, refugee tersebut adalah imigran ilegal. Namun jika melihat pada kepentingan refugee dalam hukum internasional yang telah diuraikan sebelumnya, maka kedatangan tidak sah para refugee tersebut merupakan suatu diskresi terhadap peraturan migrasi Australia yang kemudian dikooptasi dalam perkembangan hukum migrasi. Visa yang disediakan Australia untuk kategori tersebut bernama "Refugee Visa (subclass 200)" atau Protection Visa

\footnotetext{
10 ILC Report 2006, 51; Al-Adsani v. United Kingdom [ECHR], Judgment 21 November 2001, Application No. 35763/97.

Artikel 14 (1) Universal Declaration of Human Rights.

Introductory Note of The 1948 Universal Declaration of Human Rights.

Article 13 (1) Australia Migration Act 1958.

Justin Healey ed., Refugee: Managing Australia's Borders (The Spinney Press, 2009) 7.

15 Department of Immigration and Border Protection-Australia, 'Protection Monitoring and Analysis Section: Asylum Trends - Australia: 2012-13 Annual Publication' 24 <https://www.immi.gov.au/ media/publications/statistics/immigration-update/asylum-trends-aus-2012-13.pdf> diakses 23 Maret 2014.

16 Jane McAdam, 'Editorial: Australia and Asylum Seekers' (2013) 25 International Journal of Refugee Law 435, 437.
} 
dalam kategori Humanitarian Immigrant. Dengan demikian dapat disimpulkan bahwa meskipun kedatangan refugee melalui cara yang tidak sah, namun karena terdapat kepentingan humanity yang dibawa refugee maka negara berkewajiban untuk tidak menolak kedatangannya.

Selain itu, terdapat kewajiban lain negara untuk tidak memulangkan refugee ke negara asalnya dalam situasi yang dapat membahayakan keselamatan refugee. Kewajiban ini dikenal dengan prinsip non-refoulement. Prinsip non-refoulement diatur dalam Artikel 33 Konvensi Refugee mengatur tentang larangan pengembalian refugee ke negara asalnya yang berbunyi: "No Contracting State shall expel or return (refouler) a refugee in any manner whatsoever to the frontiers of territories where his life or freedom would be threatened on account of his race, religion, nationality, membership of a particular social group or political opinion." Prinsip tersebut juga diadopsi dalam Artikel 3 the European Convention for the Protection of Human Rights and Fundamental Freedom, Artikel 22 the American Convention on Human Rights, Artikel II the OAU Refugee Convention, dan Artikel 2 the Cairo Declaration on the Protection of Refugees and Displaced Persons in the Arab World. Prinsip ini merupakan prinsip utama dalam hukum refugee untuk memastikan keselamatan refugee dimanapun mereka berada dan berlaku sebagai complicity principle atau jus cogens $^{17}$ dalam customary international law. ${ }^{18}$ Dengan kata lain, prinsip ini mengikat semua negara tanpa perlu adanya aksesi terhadap Konvensi Refugee maupun peraturan refugee lainnya.

Setiap negara juga wajib untuk memberikan hak-hak dasar refugee sebagai konsekwensi atas penerimaan refugee di negaranya. Hak-hak krusial yang dimiliki refugee di antaranya adalah:

a. Hak untuk hidup, kemerdekaan dan keamanan

b. Hak untuk mencari dan mendapatkan perlindungan

c. Bebas dari penganiayaan yang bersifat menurunkan martabat manusia

d. Bebas dari perbudakan

e. Pengakuan sebagai seorang yang mampu melakukan tindakan hukum

f. Bebas dari penangkapan dan penahanan

g. Bebas untuk berpendapat dan berekspresi

h. Hak untuk mendapatkan edukasi

i. Hak untuk berpartisipasi dalam komunitas

j. Dan lain-lain. $^{19}$

Demikian kerangka perlindungan hukum terhadap refugee dalam hukum internasional sebagai bentuk pengakuan atas kepentingan humanity yang ada dalam refugee sebagai legal immigrant.

17 Stephen H. Legomsky, Op.Cit. 568.

18 Guy S Goodwin-Gill, 'Editorial: The Dynamic of International Refugee Law’ (2014) 25 International Journal of Refugee Law 651, 652.

19 Kate Jastram, Op.Cit. 16. Lihat juga Konvensi Refugee. 
Detention Sebagai Fasilitas Penanganan Refugee Terkait National Security (Dalam Hukum Nasional Australia)

Berdasarkan hukum nasional Australia ${ }^{20}$, penahanan dilakukan terhadap setiap orang yang memasuki wilayah Australia tanpa visa sampai orang tersebut mendapat visa atau dikeluarkan dari Australia. Pada kasus refugee yang memasuki wilayah Australia tanpa visa, mereka mendapat penahanan sementara dan ditempatkan di Immigration Detention Centre. Australia memiliki 25 Detention Centre, termasuk di Christmas Island dan Nauru Island. ${ }^{21}$ Detention Centre tersebut memiliki 4 kategori besar yaitu:

a. Immigration Detention Centre (IDC) dengan fasilitas keamanan tertinggi;

b. Immigration Residential Housing (IRH) berada di lingkungan domestik Australia;

c. Immigration Transit Accommodation (ITA) bersifat tertutup dan tingkat pengamanan lebih rendah dibanding IDC.

d. Alternative Place of Detention Centre (APOD) yang digunakan untuk menahan imigran ilegal namun memiliki resiko bahaya minimal terhadap komunitas Australia.

Penggunaan Detention Centre sebagai tempat penahanan para refugee dengan maksud: a. Refugee dapat hadir secara fisik setiap waktu saat proses pengajuan visa, dan jika pengajuan visa ditolak, mereka dapat langsung dikeluarkan dari Australia.

b. Refugee dapat hadir secara fisik setiap saat guna pemeriksaan kesehatan untuk kepentingan pengajuan visa.

c. Refugee yang memasuki wilayah tanpa ijin tersebut tidak dapat memasuki wilayah komunitas masyarakat Australia sampai identitas dan status mereka dinilai dan visa diberikan. ${ }^{22}$

Terdapat fasilitas yang dapat dinikmati refugee dalam Detention Centre, yaitu: pelayanan medis dan gigi; pelayanan kesehatan fisik dan psikologis; program pendidikan untuk dewasa dan anak, termasuk pendidikan bahasa Inggris; Aktivitas budaya; Kelas tentang kebudayaan Australia; aktivitas olahraga; pelayanan agama; Ketersediaan telepon, koran, dan televisi; akses tidak terbatas untuk air, teh, kopi, susu, dan gula. ${ }^{23}$ Selama berada di Detention Centre, refugee dapat mengajukan permohonan Protection Visa yang ditujukan kepada Australian Government Department of Immigration and Border Protection (yang sebelumnya bernama Department of Immigration and Citizenship). Tenggang waktu

$20 \quad$ Articles 189 and 196 Migration Act 1958.

21 Australian Human Rights Commission, 'Asylum Seekers, Refugee and Human Rights' <https:/ /www.humanrights.gov.au/publications/asylum-seekers-refugees-and-human-rights-snapshotreport/2-onshore-detention-and> diakses 28 Maret 2014.

22 Justin Healey ed., Asylum Seekers and Immigration Detention (The Spinney Press 2013), 7. 
sampai dengan pemberian visa, refugee mendapat Bridging Visa yang menunjukkan bahwa refugee sedang dalam proses permohonan visa.

Penilaian/assessment terhadap refugee terkait resiko terhadap keamanan nasional (risk to national security) dilakukan oleh otoritas yang bernama Australia Security Intelligence Organisation (ASIO). ${ }^{24}$ ASIO adalah suatu organisasi pemerintah yang dibentuk dengan fungsinya (antara lain) mendapatkan, menghubungkan, mengevaluasi, dan mengkomunikasikan informasi terkait keamanan negara. ${ }^{25}$ Yang dimaksud keamanan negara meliputi keamanan penduduk negara Commonwealth dari: spionase; sabotase; kekerasan bermotif politik; penghasutan kekerasan komunitas; serangan terhadap sistem pertahanan Australia; tindakan campur tangan asing. ${ }^{26}$

Penilaian dari ASIO ini memiliki beban yang sangat tinggi dalam menentukan pemberian Protection Visa terhadap refugee. Jika refugee berhasil mendapatkan Protection Visa, refugee tersebut dapat hidup dalam lingkungan komunitas masyarakat Australia dan memiliki hak yang sama dengan penduduk Australia serta memperbolehkan refugee menjadi Permanent Resident (PR) di negara Australia. Namun jika permohonan visa tersebut ditolak, maka refugee akan diminta untuk meninggalkan wilayah Australia dan berpotensi besar untuk dikembalikan ke negara asalnya. Bagi mereka yang menolak keputusan penolakan pemberian visa, dapat mengajukan perkara tersebut ke Refugee Review Tribunal (RRT). RRT adalah sebuah badan hukum independen dengan kewenangan sesuai dengan Migration Act untuk meninjau penolakan pemberian visa tersebut. ${ }^{27}$

Settlement merupakan bagian dari proses lanjutan paska diberikannya Protection Visa kepada refugee. Tanpa adanya keluarga yang sebelumnya tinggal di Australia, maka penempatan refugee di wilayah Australia menjadi tugas Department of Immigration and Border Protection. Proses penempatan ini dinamakan settlement. ${ }^{28}$

Adapun alternatif lain yang ditawarkan pemerintah Australia terhadap refugee yaitu berupa opsi resettlement di negara lain (third country). Opsi alternatif ini bersifat voluntary yang artinya keputusan resettlement ada di tangan refugee. Resettlement biasa ditawarkan bagi refugee yang telah diakui sebagai refugee namun tidak memenuhi standar minimal Australia dalam beberapa item tes yang harus dipenuhi seperti kesehatan dan lain-lain atau dapat dikarenakan oleh faktor

23 Justin Healey ed., Refugee and Asylum Seekers: Immigration Detention (The Spinney Press 2003) 14.

24 Section 4 Australian Security Intelligence Organisation Act 1979.

25 Section 17 Australian Security Intelligence Organisation Act 1979.

26 Bagian 1 Australian Security Intelligence Organisation Act 1979.

27 Jane McAdam, Op.Cit. 443.

28 Elibritt Karlsen, 'Seeking Asylum: Australia's Humanitarian Program' $21<$ http:// www.aph.gov.au/binaries/library/pubs/bn/sp/seekingasylum.pdf> diakses 20 Maret 2014. 
keluarga (family reunion). Hal yang perlu diperhatikan dalam resettlement ini adalah negara ketiga/third country tersebut harus terlebih dahulu memberikan pengakuan terhadap refugee sebagai warga negaranya dan menjamin kepastian prinsip nonrefoulement. ${ }^{29}$

\section{Detention Centre Melemahkan Perlindungan Kepentingan Kemanusiaan Refugee}

Pemaparan sebelumnya

menunjukkan adanya dua kepentingan yang fundamental dalam hukum refugee internasional yaitu kepentingan humanity dari refugee dan kepentingan national security dari suatu negara. Di satu sisi, terdapat situasi refugee sebagai manusia yang membutuhkan perlindungan dan sisi lain terdapat suatu kewajiban bagi aparatur negara untuk melindungi wilayahnya dari ancaman bahaya eksternal.

Detention Centre memegang peranan penting dalam persoalan bagaimana kedua kepentingan tersebut bertemu. Bagian ini akan menjelaskan bagaimana posisi refugee di tengah pilar national security dalam negara Australia.

Berdasarkan hukum keimigrasian Australia, Detention Centre digunakan sebagai tempat penahanan sementara untuk para refugee yang memasuki wilayah Australia secara ilegal. Beberapa Detention Centre di Australia, seperti Christmas Island, Nauru, dan lainnya, sengaja dilokasikan pada wilayah terisolasi dan terpencil untuk menghindari pembauran refugee dengan komunitas masyarakat Australia dengan alasan national security. Hal ini menjadikan Detention Centre dipandang tidak jauh berbeda dengan penjara.

Penulis berpendapat bahwa Detention Centre memang memiliki esensi untuk menjaga keamanan negara di mana suatu negara berhak melakukan tindakan penahanan terhadap orang yang memasuki wilayah Australia secara ilegal. Hal tersebut penting dilakukan di tengah peningkatan fenomena terorisme sekarang ini. Dikaitkan dengan Artikel 9 (1) International Covenant on Political and Civil Rights yang menyatakan "Everyone has the right to liberty and security of person. No one shall be subjected to arbitrary arrest or detention. No one shall be deprived of his liberty except on such grounds and in accordance with such procedure as are established by law", maka Detention Centre dimaknai sebagai tempat persinggahan sementara sampai seseorang dinyatakan terbukti sebagai refugee. Apabila individu tersebut diketahui kemudian sebagai seorang kriminal perang atau pelaku yang melakukan tindak criminal non-politik serius, maka prinsip nonrefoulement tidak berlaku padanya sehingga kemungkinan besar ia dapat dikembalikan ke negara asalnya. ${ }^{30}$ Detention Centre memiliki fungsi positif

292001 Declaration of States Parties to the 1951 Convention and/or its 1967 Protocol relating to the Status of Refugee. 
terkait filtering terhadap Illegal Maritime Arrivals (IMA).

Namun meskipun Detention Centre memiliki fungsi positif dalam pilar keamanan negara, penulis ingin menekankan adanya situasi dalam Detention Centre yang justru memperlemah kepentingan humanity refugee dengan alasan national security. Di pertengahan tahun 2012, terdapat sejumlah refugee yang telah tinggal di Detention Centre selama 1,5 dan 2 tahun saat akhirnya menerima panggilan security assessment. ${ }^{31}$ Perkiraan total masa tinggal refugee di Detention Centre dihitung dari awal kedatangan di Australia sampai pertengahan 2012 adalah 2-3 tahun tanpa kejelasan tentang keputusan visa. Tidak hanya itu, seorang anak juga lahir di Detention Centre dan telah tinggal di sana selama lebih dari 2 tahun. ${ }^{32}$ Masa di mana refugee menunggu kepastian keputusan visa dinamakan Detention Pending Removal.

Lamanya Detention Pending Removal ini perlu dikritisi sebagai suatu tindakan yang menelantarkan refugee, dalam arti bahwa pemerintah Australia tidak memberikan perhatian sepenuhnya pada kepentingan humanity para refugee. Hal tersebut juga dapat dianggap sebagai pelanggaran terhadap Artikel 31 (1) Konvensi Refugee yang menyatakan:
The Contracting States shall not impose penalties, on account of their illegal entry or presence, on refugees who, coming directly from a territory where their life or freedom was threatened in the sense of Article 1, enter or are present in their territory without authorization, provided they present themselves without delay to the authorities and show good cause for their illegal entry or presence.

Secara implisit, berdasarkan Konvensi Refugee, nampak bahwa Detention Pending Removal pada kasus di atas merupakan bentuk hukuman atau penalties terhadap refugee. Artikel tersebut menunjukkan bahwa jika seorang refugee memasuki wilayah suatu negara, selama mereka langsung melaporkan dirinya pada otoritas yang berlaku dan menunjukkan itikad baik di balik keberadaan ilegal (IMA) mereka, maka penahanan tidak dapat dilakukan terhadapnya.

Tindakan penelantaran refugee di Detention Centre selama bertahuntahun sering disebut sebagai "Administrative Detention" di mana penahanan terjadi karena lambatnya proses administrasi dari pihak ASIO terkait security assessment. ${ }^{33}$ Tidak ada informasi kejelasan atas proses security assessment selama masa administrative detention serta tranparansi security assessment sehingga refugee tidak dapat mengetahui atau menguji dasar penilaian ASIO terhadap mereka. ${ }^{34}$ Situasi tersebut tidak hanya mempengaruhi nasib refugee di masa

$30 \quad$ Kate Jastram, Op.Cit, 41.

31 Ben Saul, 'Dark Justice: Australia's Indefinite Detention of Refugees on Security Grounds under International Human Rights Law' (2012) 13 Melbourne Journal of International Law 1, 3 <http:/ /law.unimelb.edu.au/_data/assets/pdf_file/0007/1687381/Saul.pdf> diakses 28 Maret 2014. 
depan namun juga menyebabkan tekanan mental pada refugee. Diinformasikan terdapat 1.100 kasus self-harm di Detention Centre pada tahun 2010-2011 sebagai aksi demontrasi mereka terhadap ketidakjelasan status visa mereka. ${ }^{35}$

Tidak hanya itu, lokasi Detention Centre yang berada di wilayah terisolasi dan tertutup untuk umum dengan penjagaan ketat mempertegas bahwa refugee dalam Detention Centre tidak dapat membaur atau melakukan komunikasi dengan komunitas masyarakat Australia dan seakan memberi garis keras untuk tidak memberi informasi apapun terhadap media. Hal ini memberi kesan bahwa pemerintah Australia tidak ingin Detention Centre mendapat sorotan perhatian masyarakat internasional terkait kondisi refugee di Detention Centre.

Eksistensi administrative detention menyebabkan timbulnya ketidakseimbangan antara kepentingan humanity dan kepentingan national security, dalam hal ini, kepentingan humanity menjadi lemah. Suatu solusi diperlukan untuk menyeimbangkan kedua kepentingan tersebut dalam hukum refugee.
Pertama, pembatasan waktu administrative detention harus diberlakukan supaya refugee mendapat kepastian proses visa yang ia jalani. Mengambil contoh, the US Supreme Court telah memberlakukan ketentuan maksimal penahanan 6 bulan refugee di US Detention Centre. ${ }^{36}$ Hal ini untuk menghindari adanya "penelantaran" refugee di Detention Centre dan memberikan kepastian hukum yang jelas kepada refugee.

Kedua, transparansi security assessment oleh ASIO perlu dilakukan dengan tujuan refugee dapat mengetahui faktor kegagalan pemberian visa (dalam kasus pemerintah Australia tidak memberikan visa kepada refugee). Hal ini dapat meminimalisir adanya potensi praduga sepihak tanpa konfirmasi pada refugee serta menyeimbangkan posisi refugee dalam pengajuan uji materiil penolakan visa dalam RRT.

Kedua solusi tersebut menempatkan refugee dan pemerintah Australia dalam posisi seimbang dimana di satu sisi, refugee dengan kepentingan humanity-nya mendapat suatu jaminan akan keberlangsungan hidupnya dengan status visa yang jelas. Di sisi lain, solusi tersebut tidak menghilangkan fungsi aparatur negara Australia untuk tetap

Ibid. 31 .

34 Anonim, 'Communication to the United Nations Human Rights Committee' 28 August 2011, 6 <https://senate.aph.gov.au/submissions/comittees/viewdocument.aspx?id=229128ab-d97b4dab-9b97-bcf31229b81c> diakses 29 Maret 2014.

$35 \quad$ Ibid. 7.

36 Zadvydas v. Davis, 533 US 678, "Certiorari To the United States Court of Appeals For The Fifth Circuit” No. 99-7791 <https://supreme.justia.com/cases/federal/us/533/678/case.html> diakses 29 Maret 2014. 
mengedepankan kepentingan national security dalam penanganan refugee.

\section{PENUTUP}

International Covenant on Political and Civil Rights sebagai lexgeneralis dan The 1951 Convention relating to the Status of Refugees sebagai lex specialist dalam dunia hukum internasional refugee telah mengatur bagaimana perlindungan hukum diberikan kepada refugee di taraf internasional dengan latar belakang kepentingan humanity. Kerangka hukum tersebut dikonstruksikan untuk menjamin hakhak refugee baik dalam situasi legal entry maupun illegal entry. Namun dalam prakteknya, negara yang seharusnya bertanggungjawab atas perlindungan hukum tersebut justru mengesampingkan kepentingan humanity para refugee dengan latar belakang kepentingan national security. Posisi yang tidak seimbang antara kepentingan humanity dan kepentingan national security dalam penanganan kasus refugee (Illegal Maritime Arrivals) ditunjukkan oleh fenomena yang terjadi di Detention Centre di Australia.

Dua masalah krusial yang melemahkan kepentingan humanity refugee tersebut ialah ketidakpastian jangka waktu pemberian visa yang disebabkan assessment oleh ASIO yang bersifat tertutup. Hal ini memberi akibat pada refugee harus bertahun-tahun hidup di Detention Centre. Ketidakterbukaan assessment oleh ASIO tersebut juga membuat posisi refugee sulit untuk mengetahui faktor kegagalan pemberian visa untuk kepentingan di RRT.

Solusi yang ditawarkan dalam tulisan ini untuk mengatasi dua masalah krusial tersebut adalah pertama, adanya batas jangka waktu maksimum pemberian visa untuk menjamin kepastian hukum bagi refugee selama berada di Detention Centre. Kedua, transparansi assessment oleh ASIO supaya dapat menyeimbangkan kedudukan refugee pada saat proses banding di RRT. Kedua solusi tersebut merupakan bentuk usaha penyeimbangan kepentingan humanity para refugee dan kepentingan national security suatu negara dalam hukum refugee internasional.

\section{DAFTAR BACAAN}

\section{Buku}

Healey, Justin, ed., Refugee and Asylum Seekers: Immigration Detention (The Spinney Press 2003). , Refugee: Managing Australia's Borders (The Spinney Press 2009). Asylum Seekers and Immigration Detention (The Spinney Press 2013).

Senker, Cath, Migration and Refugees (Evan Brothers Limited 2008).

\section{Jurnal}

Goodwin-Gill, Guy S., 'Editorial: The Dynamic of International Refugee 
Law' (2014) 25 International Journal of Refugee Law 651.

Kennedy, David, 'International Refugee Protection' (1986) 8 Human Rights Guarterly 1.

Legomsky, Stephen H., 'Secondary Refugee Movements and the Return of Asylum Seekers to Third Countries: The Meaning of Effective Protection' (2003) 15 International Journal of Refugee Law 567.

McAdam, Jane, 'Editorial: Australia and Asylum Seekers' (2013) 25 International Journal of Refugee Law 435.

\section{Internet}

Anonim, 'Communication to the United Nations Human Rights Committee' 28 August 2011, 6 <https:// senate.aph.gov.au/submissions/

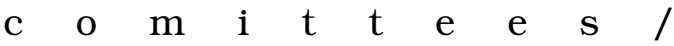
viewdocument. aspx?id=229128abd97b-4dab-9b97-bcf31229b81c> diakses 29 Maret 2014.

Australian Human Rights Commission, 'Asylum Seekers, Refugee and Human Rights <https:// www.humanrights.gov.au / publications / asylum-seekersrefugees-and-human-rightssnapshot-report/2-onshoredetention-and $>$ diakses 28 Maret 2014.

Department of Immigration and Border Protection-Australia, 'Protection Monitoring and Analysis Section:
Asylum Trends - Australia: 2012-13 Annual Publication' 24 <https:// www . i m mi.gov . a u / media / publications/statistics/immigrationupdate/asylum-trends-aus-201213.pdf> diakses 23 Maret 2014.

Department of Immigration and Citizenship, 'Asylum Statistic Australia: Quarterly Tables - March Quarter 2013, 2 <http:// www.immi.gov.au / media / publications/statistics/asylum / _files/asylum-stats-march-quarter2013.pdf> diakses 20 Maret 2014.

Ewing, John, 'Case 30: Universal Human Rights? The Case of MV Tampa' <http://www.oup.com.au/_data/ assets/pdf_file/0020/125615/ Case_30.pdf $>$ diakses 18 Maret 2014.

Jastram, Kate, dan Marilyn Achiron, 'Refugee Protection: A Guide to International Refugee Law' 6 <http:/ / ww w.refworld.org / pdfid / 3cd6a8444.pdf $>$ diakses 18 Maret 2014.

Karlsen, Elibritt, 'Seeking Asylum: Australia's Humanitarian Program' 21 <http://www.aph.gov.au / binaries/library/pubs/bn/sp/ seekingasylum.pdf $>$ diakses 20 Maret 2014.

Martin, Daniel C., dan James E. Yankay, 'Annual Flow Report: Refugees and Asylees: 2012' 1 <http:// www.dhs.gov/sites/default/files / publications/ois_rfa_fr_2012.pdf> diakses 18 Maret 2014. 
Saul, Ben, 'Dark Justice: Australia's Indefinite Detention of Refugees on Security Grounds under International Human Rights Law' (2012) 13 Melbourne Journal of International Law 1, $3<\mathrm{http}$ // law.unimelb.edu.au/_data/assets/ pdf_file/0007/1687381/Saul.pdf> diakses 28 Maret 2014. 
